\title{
ANALISIS PERANCANGAN ALAT BANTU BONGKAR YANG ERGONOMIS DAN MENGURANGI BIAYA DEBIT NOTE UNTUK PRODUK REMOT MODEL V6 DI PT. HEI
}

\author{
Beni Abidin ${ }^{1}$ \\ ${ }^{1}$ Jurusan Teknik Industri, Fakultas Teknik, Univesitas Singaperbangsa Karawang \\ Jl. HS. Ronggowaluyo Telukjambe Timur Karawang, \\ Email: 1510631140022@student.unsika.ac.id
}

\begin{abstract}
In various industries, many production processes are still done manually so that human labor plays a very important role. Based on the results of research and data processing with ergonomic methods, it is known that the anthropometric data used to design the ergonomic design of the $v 6$ remote disassembly tool are Tp, Tsb and Ps. The size of the anthropometry of the worker's body after processing the data using the 5th percentile, 50th percentile and 95th percentile used for design reference, the dimensions of each size were obtained, namely: Tp $94.2 \mathrm{~cm}$, Tsb $100.2 \mathrm{~cm}$ and Ps $20.4 \mathrm{~cm}$. In addition, from the calculation results, the average difference in $N G$ reduction in remote disassembly $v 6$ is obtained on average before using the tool the number of NG is 12.3 and after using the tool the average number of $N G$ is 1.5. The debit note fee issued by the company per 10 days of dismantling the remote v6 before using the tool is Rp. 2,583,000 and after using the tool Rp.378,000. So to solve this problem it is necessary to design an appropriate tool design where the results of the percentile size data are used in tool design and in the design of making tools the materials used are Aluminum As $10 \mathrm{~mm} x 350 \mathrm{~mm}$, Iron Plate $100 \times 100 \times 1.5 \mathrm{~mm}$, Plate Dural Aluminum $155 \times 70 \times 140 \mathrm{~mm}$ and Stainless $0.8 \times 50 \mathrm{~mm}$ with a total tool making price of Rp. 1,276,060
\end{abstract}

Keywords: Ergonomics; Anthropometry; design

\begin{abstract}
ABSTRAK
Di berbagai industri, banyak proses produksi yang masih dikerjakan secara manual sehingga tenaga kerja manusia merupakan peranan yang sangat penting. Berdasarkan hasilpenelitian dan pengolahan data dengan metode ergonomi maka diketahui data antropometri yang digunakan untuk merancang perancangan alat bantu bongkaran remote v6 yang ergonomis adalah Tp, Tsb dan Ps. Besar ukuran antropometri tubuh pekerja setelah pengolahan data dengan menggunakan persentil 5, persentil 50 dan persentil 95 yang digunakan untuk acuan perancangan didapatlah dimensi ukuran masing-masing yaitu: Tp 94,2cm, Tsb 100,2 cm dan $P s$ 20,4 cm. Selain itu dari hasil perhitungan, rata-rata selisih penurunan NG bongkaran remot $v 6$ didapat rata-rata sebelum menggunakan alat jumlah $N G 12,3$ dan sesudah menggunakan alat menjadi rata-rata 1,5 jumlah NG. Biaya debit note yang dikeluarkan perusahaan per 10 hari pengerjaan bongkaran remote $v 6$ sebelum menggunakan alat sebesar Rp. 2.583.000 dan setelah .menggunakan alat sebesar Rp.378.000. Maka untuk memecahkan masalah tersebut perlu dirancang perancangan alat yang sesuai dimana hasil data ukuran persentil digunakan dalam perancangan alat dan dalam rancangan pembuatan alat bahan yang digunakan adalah As Alumunium Ø $10 \mathrm{~mm} \times \mathrm{p} 350 \mathrm{~mm}$, Plat Besi $100 \times 100 \times 1,5 \mathrm{~mm}$, Plat Dural Alumunium $155 \times 70 \times 140 \mathrm{~mm}$ dan Stainless $\varnothing 0.8 \times 50 \mathrm{~mm}$ dengan total harga pembuatan alat sebesar Rp.1.276.060.
\end{abstract}

Kata kunci: Ergonomi; Anthropometri; Perancangan 


\section{PENDAHULUAN}

PT HEI merupakan perusahaan yang bergerak dalam industri elektronik. Perusahaan yang memproduksi berbagai jenis remot seperti model V6, L-Con, S-Con, dll. PT HEI merupakan perusahaan yang produksinya memiliki sistem make to order. Perusahaan akan memenuhi permintaan customer untuk memproduksi produk yang diinginkan dengan melakukan pemesanan terlebih dahulu. PT HEI memiliki 2 departemen produksi yaitu MR dan IR, di departemen IR banyak model remot tv yang di produksi salah satunya yaitu model remot V6 untuk NG remot total dan NG proses line akan diambil oleh operator bongkaran dari PT. Hansung untuk proses bongkar remot dan diambil kembali PCB dan rubber OK nya. Untuk NG scrat, step, dented, white mark, printing, bari, shortmolding, dll. Akan diambil oleh standby dari PT. Shinsung untuk proses perbaikan remot karena PT. Shinsung merupakan supplier dari komponen top case dan bottom case. Dan untuk NG rubber akan diambil oleh standby dari PT. Mirai untuk proses perbaikan rubber pada remot karena PT.Mirai merupakan supplier dari komponen rubber.

Pekerjaan membongkar remot yang dilakukan oleh operator standby PT. Pampas, PT. Shinsung, PT. Mirai serta oleh operator bongkaran dari PT. Hansung, dilakukan secara manual, dengan cara membantingkan bagian ujung bawah remot model V6 ke lantai sehingga bagian top case dan bottom case akan terbuka. Membongkar remot dengan cara seperti itu akan menyebabkan beberapa PCB remot menjadi rusak fungsi yang tidak bisa dideteksi secara manual. Kemudian PCB hasil bongkaran akan digunakan kembali di line produksi untuk dirakit menjadi remot lagi, sehingga PCB rusak pun akan terbawa produksi lagi, dan remot akan tidak fungsi lagi di mesin zig dan menjadi NG fungsi. NG fungsi hasil bongkaran tersebut akan menjadi debit note bagi PT. Pampas, karena PT. Pampas merupakan supplier dari PCB remot V6 dan biayadebit note yang harus dibayar sebesar Rp.21.000/NG.

Dari hasil pengamatan awal pekerja yang melakukan bongkaran remot model V6 merasa kurang nyaman, dimana jari tangan kadang ikut terbanting ke lantai, tangan mudah pegal karena harus mengayun kencang agar remot terbongkar, kaki dengan posisi duduk bersila terlalu lama yang menyebabkan kesemutan, punggul yang pegal karena harus membungkuk pada saat tangan akan menjangkau atau menyimpan remot. Karena ketidak ergonomisan proses kerja bongkaran remot dan menyebabkan besarnya debit note untuk PT. Pampas. Maka perlu adanya perancangan alat bantu yang dapat membantu proses kerja bongkaran remot model V6. Dimana dalam penelitian ini, akan dilakukan pemberian quisioner kepada pekerja yang melakukan proses bongkaran remot model V6 mengenai bagian tubuh yang di keluhkan setelah melakukan bongkaran remot. Kemudian melakukan pengukuran tubuh untuk perhitungan antropometri, sebagai dasar ukuran dimensi alat yang akan dirancang. Penelitian ini juga membandingkan jumlah debit note PT. Pampas karena PCB rusak akibat proses bongkaran sebelum dan sesudah perancangan alat. Oleh karena itu, berdasarkan paparan latar belakang diatas. Peneliti melakukan penelitian tentang "Analisis perancangan alat bantu bongkar yang ergonomis dan mengurangi biaya debit note untuk produk remot model V6 di PT. HEI."

\section{METODE PENELITIAN}

Jenis penelitian yang digunakan dalam penelitian ini adalah penelitian (Action Research), yaitu suatu jenis penelitian yang dilakukan untuk menguji, mengembangkan, menemukan dan menciptakan tindakan baru sehingga tindakan tersebut kalau ditetapkan dalam pekerjaan dapat proses pelaksanaan kerja akan lebih mudah, lebih cepat dan hasilnya lebih banyak dan berkualitas. Jenis penelitian yang digunakan dalam penelitian ini bersifat deskriptif kuantitatif yang menurut Wirartha (dalam Sarjono dan Kuncoro, 2014:41) yaitu menganalisis, menggambarkan dan meringkas berbagai kondisi, situasi dari berbagai data dalam bentuk angka-angka yang dikumpulkan dari hasil analisis dan wawancara atau pengamatan mengenai masalah yang diteliti yang terjadi di lapangan. Penelitian ini dilakukan di PT.HEI pada bagian operator standbay bongkaran remot V6, data yang diambil dari perusahaan yaitu jumlah NG remote V6 periode tahun 2020 serta data quisioner dan wawancara terhadap operator. Adapun memecahan masalahnya mengunakan metode ergomoni dimana dari hasil keluhan operator dihitung anthropometrinya untuk dilakukan perancangan alat bantu yang sesuai dalam permasalahan penelitian. 


\section{HASIL DAN PEMBAHASAN}

\section{Analisis Keluhan dan Kebutuhan Operator}

Analisis dari hasil wawancara kepada operator standby di PT.HEI diketahui bahwa pengaruh jumlah NG disebabkan karena proses pengerjaan bongkaran remote v6 yang manual serta pengerjaanya yang menyebakan rasa pegal pada punggung, kaki, dan lengan atas, serta rasa sakit pada jari tangan, telapak tangan, dan pergelangan tangan, karena proses bongkaran dengan cara digetokan kelantai dengan posisi tubuh duduk bersila dilantai.

Setelah dilakukan wawancara terhadap operator stanby hasil interpretasi kebutuhan operator didapatlah pernyataan untuk perancangan alat dimana:

- Alat Harus Kuat

Alat tersebut terbuat dari bahan yang cukup kuat untuk menopang remote terus menerus.

- Tahan Lama

Pekerja ingin alat tersebut tidak mudah rusak jika digunakan dalam jangka waktu lama.

- Perawatan Mudah

Alat mudah diperbaiki sehingga operator tidak sulit untuk merawat alat.

- Mudah Penggunaannya

Pekerja ingin alat tersebut nantinya mudah dalam proses mengerjakan bongkaran remote.

- Sederhana Alatnya

Operator ingin alat yang penggunaanya sederhana tetapi fungsinya maksimal.

- Mengurangi Keluhan Fisik Pekerja

Alat tersebut dapat mengurangi keluhan fisik pada saat pengerjaan bongkaran remote.

\section{Analisis Berdasarkan Anthropometri}

Analisis dilakukan dengan mencari acuan dimensi bagian tubuh sesuai dengan perhitungan anthropometri sebagai langkah dalam perbaikan. Data antropometri merupakan data yang diperlukan dalam menentukan ukuran-ukuran dalam perancangan sehingga hasil rancangan akan sesuai dengan dimensi ukuran tubuh pekerja. Data antropometri ini diperoleh dari hasil pengukuran dimensi tubuh pekerja di PT.HEI pada bagian standby. Ukuran yang digunakan adalah tinggi pinggang, tinggi siku bediri dan panjang siku.

Selanjutnya, dilakukan uji normalitas data, uji kecukupan data, uji kersagaman data didapat bahwa data seragam. Dapat dilihat pada tabel dibawah ini:

Tabel 1. Perhitungan Uji Keseragaman Data Anthropometri

\begin{tabular}{cccccccc}
\hline No. & Pengukuran & Simbol & $\overline{\boldsymbol{X}}$ & $\mathbf{a}$ & BKA & BKB & Keterangan \\
\hline 1. & Tinggi pinggang & Tp & 94,2 & 1 & 96,2 & 92,2 & Data seragam \\
2. & Tinggi siku berdiri & Tsb & 100,2 & 0,9 & 102,2 & 98,2 & Data seragam \\
3. & Panjang siku & Ps & 40,4 & 0,9 & 42,2 & 38,2 & Data seragam \\
\hline
\end{tabular}

Sumber: Hasil Pengolahan Data

Tabel 2. Perhitungan Uji Kecukupan Data Anthropometri

\begin{tabular}{cccccc}
\hline No. & Pengukuran & Simbol & N & $\mathbf{N}^{\prime}$ & Keterangan \\
\hline 1. & Tinggi pinggang & Tp & 10 & 0,2 & Data cukup \\
2. & Tinggi siku berdiri & Tsb & 10 & 0,2 & Data cukup \\
3. & Panjang siku & Ps & 10 & 0,8 & Data cukup \\
\hline
\end{tabular}

Sumber: Hasil Pengolahan Data

Setelah dilakukan uji statistik, maka dari hasil tersebut dapat dihitung untuk mengetahui ukuran dimensi masing-masing anthropometri yang digunakan dalam perancangan alat. 
Tabel 3. Ukuran Dimensi Anthropometri masing-masing

\begin{tabular}{cccccc}
\hline \multirow{2}{*}{ No. } & Pengukuran & Simbol & \multicolumn{3}{c}{ Persentil (cm) } \\
& & 5-th & 50-th & 95-th \\
\hline 1. & Tinggi pinggang & Tp & 92,6 & 94,2 & 95,8 \\
2. & Tinggi siku berdiri & Tsb & 98,7 & 100,2 & 101,7 \\
3. & Panjang siku & Ps & 38,9 & 40,4 & 41,9 \\
\hline
\end{tabular}

Sumber: Hasil Pengolahan Data

\section{Analisis Selisih Penurunan NG}

Analisi dilakukan ntuk mengetahui dan membuktikan adanya pengaruh antara rata-rata penurunan NG kita perlu melakukan uji statistik dengan membandingkan kedua hasil tersebut. Dalam uji ini digunakan uji Paired Sample T-Test dengan aplikasi SPPS diketahui bahwa biaya penurunan jumlah NG pada saat tidak menggunkan alat dengan penurunan jumlah NG pada saat menggunakan akan tidak sama.

Dari hasil tersebut dilakukan perhitungan selisih biaya penurunan NG dimana opetaor bekerja sebelum menggunakan alat dan sesudah menggunakan alat, selisih hasilnya dapat dilihat pada tabel berikut:

Tabel 4. Selisih Pengeluaran Biaya Debit Note

\begin{tabular}{lcr}
\hline \multicolumn{3}{c}{ Selisih Pengeluaran Biaya Debit Note } \\
& $\begin{array}{c}\text { Pengerjaan( } \\
\text { Hari) }\end{array}$ & $\begin{array}{r}\text { Biaya yang } \\
\text { dikeluarkan }\end{array}$ \\
\hline Ng Tanpa Alat Bantu & 10 & Rp.2.583.000 \\
Ng Dengan Alat Bantu & 10 & Rp.378.000
\end{tabular}

Sumber: Hasil Pengolahan Data

\section{Analisis Perancangan Alat}

Peracangan alat dilakukan sesuai dengan hasil data-data anthropometri dan kuisoner. Setelah perhitungan ukuran persentil diperoleh, maka langkah selanjutnya adalah menentukan ukuran perancangan alat bantu dapat dilihat pada table berikut.

Tabel 5.Ukuran Perancangan Alat

\begin{tabular}{cccccc}
\hline \multirow{2}{*}{ No } & \multirow{2}{*}{ Bagian Alat } & \multicolumn{5}{c}{ Ukuran (cm) } \\
& & Panjang & Lebar & Tinggi & Diameter \\
\hline 1 & Handle & 13 & & & 1 \\
2 & Plat Pembuka & 9,1 & 5,5 & 0,15 & \\
3 & Tuas & 2 & & & 1 \\
4 & Dudukan & 11,4 & 4,5 & 7,2 & \\
5 & Dudukan tuas & 4,5 & 1 & 3,5 & \\
6 & Lubang tuas & & & & 1 \\
7 & Nuts & 5 & & & 0.8 \\
8 & Dudukan plat & 4,5 & 0,8 & 1,9 & \\
\hline
\end{tabular}

Sumber: Hasil Pengolahan Data 
Setelah diketahui ukuran masing-masing untuk perancangan, maka selanjutnya dilakukan perancangan gambar alat.
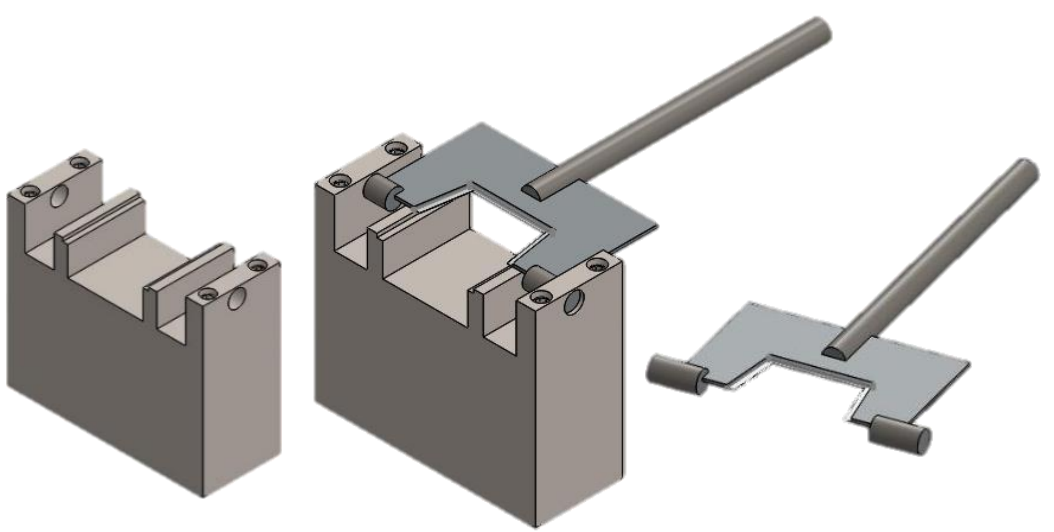

Gambar 1. Alat Bantu Bongkar

Sumber : Hasil Pengolahan Data

Adapun rincian biaya dalam pembuatan alat digunakan untuk mengetahui berapa total biaya yang dikerluarkan dalam pembuatan alat. Adapaun perhitungan bahan baku dan tenaga kerja pembuatan alat adalah sebagai berikut:

Tabel 6. Rincian Biaya Pembuatan Alat

\begin{tabular}{|c|c|c|c|c|c|}
\hline No & Bagian Alat & Bahan & Dimensi & Jumlah & Harga \\
\hline 1 & Handle & As & $\emptyset 10 \mathrm{~mm} \times \mathrm{p}$ & & \\
\hline 2 & Tuas & Almuniu & $350 \mathrm{~mm}$ & 1 Buah & $\operatorname{Rp} .12 .500$ \\
\hline 3 & Plat Pembuka & Plat besi & $100 \times 100 \times 1,5 \mathrm{~mm}$ & 1 Buah & $\mathrm{Rp} \quad .8 .000$ \\
\hline 4 & Dudukan & Plat Dural & & & \\
\hline 5 & Dudukan tuas & Alumunium & $155 \times 70 \times 140 \mathrm{Mm}$ & 1 Buah & Rp. 690.000 \\
\hline 6 & Nuts & Stainles & $\varnothing 0.8 \times 50 \mathrm{~mm}$ & 4 Buah & Rp. $\quad 5.560$ \\
\hline \multicolumn{6}{|c|}{$\begin{array}{l}\text { Jumlah Biaya Bahan Baku = Rp. } \\
986.060\end{array}$} \\
\hline No & \multicolumn{4}{|c|}{ Biaya Tenaga Kerja Pembuatan Alat (Bengkel Bubut) } & Harga \\
\hline 1 & \multicolumn{4}{|c|}{$\begin{array}{l}\text { Pemotongan } \\
\text { Bahan }\end{array}$} & Rp. 25.000 \\
\hline 2 & \multirow{2}{*}{\multicolumn{5}{|c|}{$\begin{array}{l}\text { Rp. } 265.000 \\
\text { Jumlah Biaya Tenaga Kerja = Rp. }\end{array}$}} \\
\hline & & & & & \\
\hline & \multicolumn{5}{|c|}{$\begin{array}{l}\text { Jumlah Total Pembuatan Alat Sebesar }=\text { Rp. } 986.060+\text { Rp. } 290.000= \\
\text { Rp.1.276.060 }\end{array}$} \\
\hline
\end{tabular}




\section{KESIMPULAN}

Setelah melakukan pengamatan, pengukuran antropometri dimensi tubuh, perhitungan, dan analisa keseluruhan, maka dapat ambil kesimpulan sebagi berikut.

1. Data antropometri yang digunakan untuk merancang perancangan alat bantu bongkaran remote v6 yang ergonomis adalah Tp, Tsb dan Ps. Besar ukuran antropometri tubuh pekerja setelah pengolahan data dengan menggunakan persentil 5, persentil 50 dan persentil 95 yang digunakan untuk acuan perancangan didapatlah dimensi ukuran masing-masing yaitu: Tp 94,2cm, Tsb 100,2 cm dan Ps 20,4 cm.

2. Dari hasil perhitungan, rata-rata selisih penurunan NG bongkaran remote v6 didapat rata-rata sebelum menggunakan alat jumlah NG 12,3 dan sesudah menggunakan alat menjadi rata-rata 1,5 jumlah NG. Biaya debit note yang dikeluarkan perusahaan per 10 hari pengerjaan bongkaran remote v6 sebelum menggunakan alat sebesar Rp. 2.583.000 dan setelah menggunakan alat sebesar Rp.378.000.

3. Hasil data ukuran persentil digunakan dalam perancangan alat dan dalam rancangan pembuatan alat bahan yang digunakan adalah As Alumunium Ø $10 \mathrm{~mm}$ x p $350 \mathrm{~mm}$, Plat Besi $100 \mathrm{x} 100 \mathrm{x}$ $1,5 \mathrm{~mm}$, Plat Dural Alumunium $155 \times 70 \times 140 \mathrm{~mm}$ dan Stainless $\varnothing 0.8 \times 50 \mathrm{~mm}$ dengan total harga pembuatan alat sebesar Rp.1.276.060.

\section{DAFTAR PUSTAKA}

Mulyon, J., Santoso, H., \& Tamdjaja, Y. (2013). Perancangan Alat Bantu Peletakan Sheet Dengan SistemOtomatisasi Di Pt. Madhara Aditama Utamabox. Jurnal Widya Teknik, 103116.

Irwanto, A. (2016). Perancangan Alat Bantu Fasilitas Kerja Operator Las Dengan Prinsip Ergonomi DanKonsep Value Engineering. Jurnal MATRIK, 55-67.

Nugroho, A.W. (2018). Perancangan Ulang Alat Pengupas Kacang Tanah Untuk Meminimalkan WaktuPengupasan. Skripsi, 1-140. 